\title{
Development of an Intelligent Tutoring System for English Reading Comprehension: Design Based on Philippine Public School Flexible Learning Experience
}

\author{
Day Bert R. Mariñas \\ Catablan Integrated School, Catablan, Urdaneta City, Philippines \\ Email: daybert.marinas@ deped.gov.ph

\section{Roberto R. Coloma} \\ Lananpin National High School, Pinmaludpod, Urdaneta City, Philippines \\ Email: roberto.coloma002@deped.gov.ph
}

\section{Lin V. Tadeja}

Laoac National High Schol, Poblacion, Laoac, Philippines

Email: lin.tadeja@deped.gov.ph

\section{Shaira Marie J. Castillo}

Cipriano P. Primicias National High School, San Vicente, Alcala, Philippines

Email: shairamarie.castillo@deped.gov.ph

\section{Katherine D. Tan}

Eastern Pangasinan Agricultural College, Santa Maria, Philippines

Email: katherine.tan004@deped.gov.ph

\section{Frederick F. Patacsil}

Pangasinan State University- Urdaneta City Campus

Email: frederick.patacsil@yahoo.co.uk

Received: 17 June 2021; Accepted: 20 July 2021; Published: 08 October 2021

\begin{abstract}
This paper presents an intelligent tutoring system as seen to be successful in assisting in the instruction of basic skill, particularly, reading comprehension. The goal of the study is to develop an Intelligent Tutoring System that will greatly help the Grade 7 . The system adapted considerable instructional needs of learners from early development to advanced reading comprehension skills. The developed system provided an immediate feedback to learners upon completion of an activity without requiring intervention from a Teacher. To improve the system, learners and teachers filled out survey questionnaires. The result reveals that teachers and students want the system to be user-friendly, have a user log-in, lesson content with text, audio and video as well as various types of questions in quizzes. They also perceived that the developed ITS is useful and the content is valid thus is very acceptable to be utilized by the learners. In addition, result reveals that student's reading comprehension could be improved and developed by the proposed ITS.
\end{abstract}

Index Terms: Reading Comprehension, Intelligent Tutoring System, Flexible Learning, ADDIE approach.

\section{Introduction}

Reading comprehension is one of the most challenging learning processes in which people participate, making it more difficult to teach, evaluate, and research [1]. Sometimes students think they can read, but that does not mean they understand what they read. Teachers are often one of the key factors in attaining this kind of skill. However, sometimes, they are not enough for the demand of each student. Learners differ in their attitudes, motives, and characteristics of their strengths and weaknesses while learning, which all will determine how and why they learn. They also vary in their academic styles and capacity to learn [2]. 
Within this context, distinct learning experiences take place, presenting challenges not only to the learners but also to education contributors [3]. Such challenges often lead individuals to use technology just to close gaps between learners and their learning processes. As they interact with different digital technologies, they must build a digital intelligence, which must be further cultivated as it is a key competency for the future of school and work [4]

In this regard, an intelligent tutoring system has been seen to successfully assist in the instruction of basic subjects, such as mathematics or grammar. [5]. The research on the effectiveness of ITS on Kto12 Students shows the metaanalysis confirmed that ITSs are a useful strategy of intervention because they can show comparable results on reading comprehension, although it should be noted that to do this, ITS of higher intensity and longer duration than its human one-on-one intervention equivalent will be needed. However, this study found that ITSs yield a larger effect size than the standard teaching process. [6]

Additionally, an Intelligent Tutoring System aims to provide immediate and customized instruction or feedback to learners, usually without requiring intervention from a human teacher. According to Ken Koedinger, professor of human-computer interaction and psychology, Intelligent Tutoring Systems are programmed to monitor student success in real-time, include next-step hints, and select practice tasks that help students develop new skills. The most critical result of formal education is developing learners who can interpret and comprehend the texts being read in a related manner and found out that making learners fluent in reading comprehension has become one of the educational system's key aims. It should also be remembered that it plays a significant role throughout the education of a few and all academic skills. Reading comprehension has grown in popularity because of its significance. Intelligent tutoring system (ITS) research has two main goals: to provide advanced educational guidance on a one-on-one basis that is superior to standard computer-aided instruction and equivalent to that of a good human tutor, and to build and assess models of the cognitive processes involved underlying in instruction [7]. This advancement can lead to an increased learning level of students, especially in terms of reading comprehension.

According to the Programme for International Student Assessment (PISA) in 2018 [8], wherein the test assesses learner's knowledge and skills in reading, mathematics, and science, the focus was on reading in a digital environment. Reading literacy is characterized as understanding, evaluating, reflecting on, and interacting with texts to attain one's goals, improve one's knowledge and potential, and contribute to society. The Philippines, as one of the participating countries, got lower scores in reading comprehension, mathematics, and science than most of those surveyed in other nations [9].

In the Philippines, policies were put to promote the argument that reading is an important skill for learners. One example is the No Read, No Pass Policy memo in National Capital Region (NCR) DepEd memorandum order number 67 , series of 2014. This strict policy clearly states that because reading is a learning medium that promotes success, learners who come up short of their grade level do even worse than good [10]. To resolve this problem in the educational process, the ITS was an inventive approach, especially during the pandemic, wherein learners became independent learners. Unfortunately, most of them are experiencing difficulty in learning in this kind of setup.

Catablan Integrated School (CIS) is categorized as a medium-size school in Urdaneta City, Pangasinan. Based on the previous report on reading assessment, many grade seven students are struggling in their reading comprehension and identified as beginners. In the school year 2018 - 2019, 35\% of grade 7 learners are categorized as for beginners. Also, $34 \%$ in the school year 2019 - 2020. This result shows that students need help in their reading comprehension.

As a result, the researchers agreed to develop an intelligent tutoring system which is necessary and can be a great tool to enhance the level of comprehension of the learners of Catablan Integrated School especially those who struggle in this area of learning. With this system, learners can help comprehend or practice difficult concepts and manage their own learning. The system can also provide an immediate feedback on errors made by the learners without requiring intervention from a human teacher. The system will adapt to the considerable instructional needs of learners from early development to advanced reading comprehension skills. In addition, the system can help improve the total number of learners which can be taught by the system in comparison with the total number of learners a teacher can accommodate, thus, more learners can be taught. The learners can use a device and an internet connection to be able to utilize this system.

The development of this ITS is necessary for learners who needs improvement in reading comprehension especially in this time of pandemic where learners are learning from home, not in school setting. Moreover, it can also be their long-time partner throughout their learning stages, therefore, helps them develop knowledge and skills needed to become globally competent students.

The study's goal is to develop an Intelligent Tutoring System to help Grade 7 students of Catablan Integrated School improve their reading comprehension. This research will provide an answer to the following questions:

(1) To determine learners those are struggling in reading comprehension.

(2) To determine the features needed in the development of a reading comprehension system.

(3) To develop the proposed Intelligent Tutoring System to enhance the reading Comprehension of Grade 7 Students.

(4) To determine the level of acceptability of the proposed Intelligent Tutoring System to Enhance the Reading Comprehension of Grade 7 Students in terms of: 
A. Content Acceptability and Validity

a. Correctness of content

b. Efficiency

B. Technical Acceptability
a. Overall Design
b. Interactivity
c. Usability

\section{Review of Related Studies}

This chapter will focus on studies that will help the researchers attain the desired outcome and enhance the learners' reading comprehension by developing an intelligent tutoring system. Likewise, these studies will support conceptualizing how or what the intelligent tutoring system will measure in every learner.

Artificial intelligence (AI) is being used in education in Intelligent Tutoring Systems (ITSs). These systems can be beneficial since it provides digital environments that can immediately bear on student learning (Robot, 2020) [11]. Furthermore, these systems focus on an individual's needs and preferences to improve a learner's capability [12].

\subsection{Reading Comprehension}

According to Veeravagu, [13] Reading comprehension is a method of thought in which a reader chooses facts, detail, or ideas from printed materials; determines the meanings that the author intended to convey; determine how they relate to previous information, and assess their suitability and value for achieving the learner's goals. Comprehension skills are essential for a child's success and are needed for language fluency. Students will benefit from these skills in English class and all fields of academic study as well. Ashley Moore (2016) also it is the key ingredient to a successful life [14].

In addition to that, according to Elleman and Oslund's research, instructors must provide early and consistent training in knowledge, vocabulary, inference production, and comprehension monitoring to improve reading comprehension. To improve teenage reading comprehension, researchers, educators, and policymakers must work together to forego short-term improvements on measure that target low-level comprehension in favor of long-term solutions that take years to build. [15]

\subsection{Intelligent Tutoring System}

In 2019, the study was conducted on the effectiveness of intelligent tutoring systems on K-12 students' reading comprehension, based on the result of the study ITSs produce a larger effect size on reading comprehension when compared to traditional instruction, ITSs for reading produce a small effect size when compared to human tutoring. The effect size of ITSs on reading comprehension is inflated when studies use researcher-designed tests [16]. These results may be of interest to researchers and policymakers aiming to enhance reading comprehension through the use of reliable and widely available ITSs.

Based on the study of Atun [17], Intelligent Tutoring Systems are more effective than the traditional teaching methods in developing reading comprehension skills, a variety of software used as ITS but Intelligent Tutoring System for the Text Structure Strategy is the most common one in studies, and the results have differed in favor of low-reading level students. This study showed that ITS affects their level of capability or skills in reading comprehension.

Moreover, the research conducted by Meyer [18] supported that a structured test and researcher-designed interventions showed that an intelligent web-based tutoring framework for the structure strategy (ITSS) enhanced reading comprehension. The purpose of this research is to determine the efficacy of a web-based intelligent tutoring system in improving subject area reading comprehension. "The study was conducted with 128 fifth-grade classrooms within 12 school districts in rural and suburban settings. Classrooms were randomly assigned to intervention or control groups within each school. An intelligent web-based tutoring system for the structure strategy (ITSS) was used for the group's intervention within 30 to $45 \mathrm{~min}$ each week as a partial replacement for the language arts curriculum for the entire school year. The structure strategy helps learners interpret and comprehend expository texts by describing the structure of the text and constructing strategic mental interpretations of the text. The web-based tutoring system provided the structure strategy training with modeling, practice tasks, evaluation, and immediate feedback. The control classrooms used the school's language arts curriculum for the full language-arts time. Further, Computer Aided Instruction (CAI) improve the effectiveness of delivery, assist learner improve learning, provide flexible assessment and then achieve the purpose of humane education [26][27][28].

\subsection{ITS to Student Academic Performance}

According to the study of the researchers, intelligent tutoring systems for English grammar using the ITSB tool designed to facilitate the study of English grammar has a wonderful result for students, and they overcome the difficulties they faced with ease and smoothness [19]. 
In addition to that, Eryılmaz and Adabashi [20] developed "Development of an Intelligent Tutoring System Using Bayesian Networks and Fuzzy Logic for a Higher Student Academic Performance" based on the findings the evaluation of the proposed system called the fuzzy Bayesian intelligent tutoring system (FB-ITS) showed significantly satisfactory results and positive effects in terms of the students' academic performances. When the performance of the presented system was compared to the performance of traditional e-learning, it was discovered that students who studied with FBITS had a higher mean value on academic performance than students who studied with the traditional e-learning system.

\subsection{Methodology in developing ITS}

An Intelligent Tutorial System for learning in the application and management of mechanisms is made up of three models, the content domain model, student model, and tutoring model that work together with one another [21]. To achieve a proper operation of the ITS in mechanism reparation, the models of the mechanism, the Learner, and the teacher must achieve a suitable relationship. As a result, a set of rules will emerge that explain when and how such models are being used. [22] These rules are a meta-model in the sense that they control the basic models and their associated rules. The meta-model includes the functions needed to activate and deactivate the specific models. As an example, the rules that could be assumed to be found in the meta-model can consist of the following components:

IF The learner has completed a specific task

AND The tutor has a bit of confidence in its evaluation of the learner's understanding of specific tasks.

THEN The teacher will ask the learner thoroughly about the related task.

\subsection{Conceptual Framework}

This study aimed to design and develop an intelligent tutoring system to help Grade 7 students at Catablan Integrated School improve their reading comprehension. The researchers derived this study based on different tutoring concepts such as e-learning, face-to-face tutorial, e-assessment, and peer tutoring.

E-Learning can be described as an innovative method to providing a well-designed, learner-centered, interactive, and facilitated learning experience to anybody, anywhere, at any time, by using the features and tools of various digital technology as well as other types of learning materials suitable for accessible and distributed learning environments.

P2P program is a peer tutoring strategy with embedded peer tutoring for discipline-specific learning groups. In the researchers' local 'discipline,' the program was introduced with first-year psychology students, peer tutors, and class tutors.

\subsection{Research Paradigm}

This research paradigm shows the study's conceptual framework on developing the output on a Reading Comprehension Intelligent Tutoring System for Grade 7 Students in Catablan Integrated School. The research paradigm includes the input, the process, and the output.

In the Input, the researchers identified first the learners who are struggling in reading comprehension. Then, identified the features and requirements needed in the development of a reading comprehension system. Lastly, the acceptability, validity of the content, and usability of the reading comprehension system.

The researchers came up with the "Development of Reading Comprehension Intelligent Tutoring System for Grade 7 Students in Catablan Integrated School" output. In the part of the learners and teachers, it is a great help and support to have this reading comprehension tutoring system based on the results and feedback in 4.2 Table 3 . It can save more time and effort particularly in the work of the teachers compare to the manual process of reading comprehension.

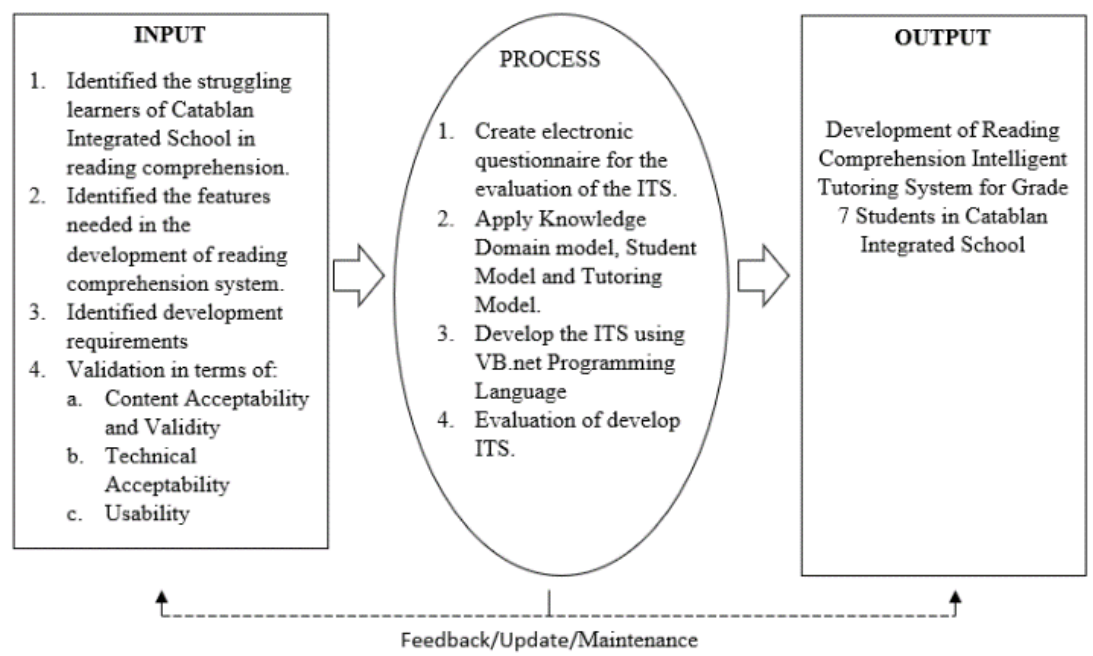

Fig.1. Research paradigm of the study 


\section{Methodology}

This chapter concentrates on discussing the research methods, designs, and procedures adhered to by the researcher to systematically answer the specific problems posed for investigation.

\subsection{Research Design}

The researchers utilized a research and development model and descriptive study to develop and evaluate the acceptability of the proposed intelligent tutoring system. To define the needed requirements for the development of the proposed ITS, a descriptive study was used, then processed with the following stages of the instructional design process, and used the basic framework based on the classical architecture of ITSs development process. The ITS content was based on the Department of Education memorandum 173 series of 2019, where the guidelines for the reading literacy program for the primary and secondary schools were stated and implemented.

The ITS was developed for Catablan Integrated School in Urdaneta City, Province of Pangasinan to provide dynamic adaptation of both learning content and clear strategy instruction with the use of technology, systematic learning process through exercises, lessons, and assessment with less intervention from a human teacher that help learners to improve or enhance the level of competency in reading comprehension and or become a proficient reader.

\subsection{Research Instrument}

Data was gathered using survey questionnaires with a Likert scale model for this study. It was used to identify the perceived appropriate features and pedagogical approach for intervention and assessment delivery of developed ITS for learners was reading comprehension enhancement.

The survey questionnaire was utilized to determine the validity and acceptability of the developed ITS program in terms of its (a) correctness of content; (b) efficiency, for the technical acceptability in terms of (a) overall design; (b) Interactivity, and the last part was the usability. These criteria were based and taken in the study of Diezmann \& Watters [23] and applied some modifications by adding some important aspects to suit the requirements of the study.

The participants of this study are composed of the following: the teachers who are conducting the quarterly reading literacy program and grade 7 learners who are enrolled in the school year 2020-2021. The teachers who assigned for the reading comprehension assessment and intervention program were asked to give some contributions for the needed learning and assessment materials, ideas with the flow or the process of the program, and learning and teaching strategies for each topic to be taught that we can use and integrate for the development of the ITS for this study.

To ensure the validity of the research instrument, researchers conducted a pilot-testing to the English teachers, IT experts, and few learners who were not included in the respondents of this study to use the ITS program and survey questionnaire for evaluation of such instrument. During the pilot-testing, the researchers observed some aspects to be added and improved, such as appropriate learning content for grade 7 learners, the correctness of learning content and assessments, additional features such as random questions in the pre-test and post-test, attractive multimedia graphics, and images content used in the ITS.

\subsection{ITS Development Process:}

The researchers designed and developed Intelligent Tutoring System using the ADDIE Instructional Model, which stands for Analyze, Design, Develop, Implement, and Evaluate.

For the past years, the proposed methodology ADDIE model has proven as an effective method as a framework in educational and training design and development programs. K. Serhat (2018). The ADDIE model is one of the most commonly used models in the instructional design area as a guide to generating a successful design. The pieces created using the ADDIE approach may be utilized in any setting, whether online or face-to-face. These phases give dynamic and adaptable recommendations for successful and efficient instruction Aldoobie [24].

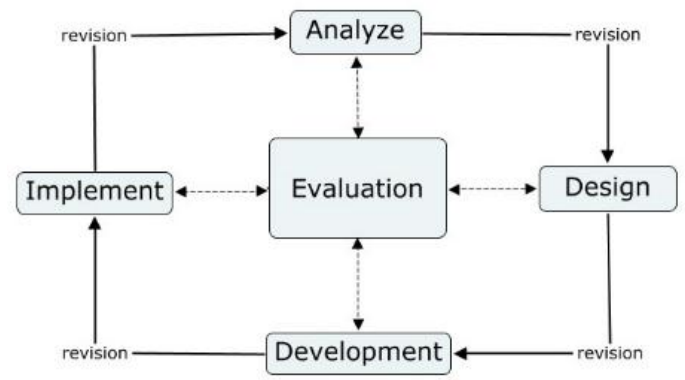

Fig.2. Intelligent Tutoring System Development Process 
The goal of this study is to develop and validate an Intelligent tutoring system to enhance the reading Comprehension for Grade 7 Students of Catablan Integrated School using the following developmental process:

During the Analysis Phase, the researchers gathered data from the previous reading comprehension assessment results to determine the number of learners who were categorized as beginner or struggling in reading comprehension from the school year 2018 to 2020 and analyzed which part of reading comprehension should the learners to gain and enhance from the intervention. The researchers also reviewed the Department of Education memorandum 173 series of 2019 called BAWAT BATA BUMABASA (Every child reads) (3Bs Initiative) in which the guidelines for the reading literacy program were stated and was used as a basis to define what topics or learning competencies to be adopted and integrated into the system.

In the Design phase, the researchers consulted instructional developer experts, teachers and IT experts to give ideas and concepts for the arrangement of instructional design based on the typical assessment and intervention plans, system requirements and features suitable for the development of ITS to suite up to the need of the leaners. These ideas and concepts should be applied to improve the quality and usability of ITS.

Development phase, The ITS was developed in the Microsoft Visual Studio 2019 environment using the VB.net for the system's functionality, which is an object-oriented programming language. MS Access was used to create and manage a database to represent, store, and retrieve data. The ITS was designed and arranged based on the flow of typical assessment and intervention plans. During this phase, the researchers used the classical ITSs architecture comprised of the following model: the domain knowledge model, student model, tutoring model, and user interface model.

According to Siemer \& Angelides [25], this architecture supports the basic three model structure, which includes the domain expertise, student knowledge and skill, and tutoring expertise that categorizes the processes, manipulates the three models bases in each of the models, and integrates an added process to coordinate the structure models. This Classical ITS architecture is showed in figure 3.

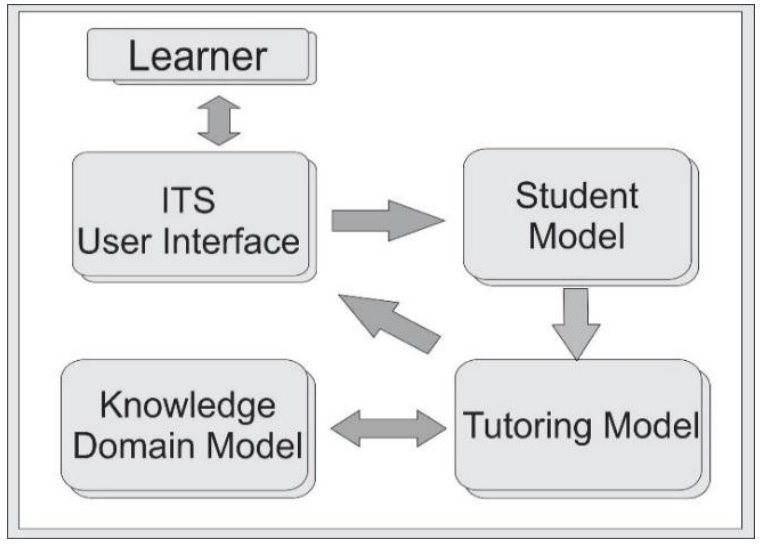

Fig.3. basic classical ITS architecture

\subsubsection{Knowledge domain Model}

The knowledge domain model in the ITS program contains materials related to reading comprehension, including learning content, test questions, quizzes, and answer keys stored in the database separate in the tutoring system. Reading materials and test questionnaires were collected from the teachers of whose assigned in the quarterly reading assessment and intervention program for reading comprehension to be incorporated into the system.

\subsubsection{Student Model}

The student model in the ITS has two separate characteristic parts of the learner, the static characteristic that includes the learner's basic information such as LRN number., name, user account, and password. The dynamic characteristic consists of the status of the leaner knowledge level, and this will be updated during the intervention process. This idea was taken from the study of Adabashi, A. [20]. The researchers collected the data of the quarterly reading assessment from the school year 2018 to 2020 to determine the percentage number of the learners defined as the beginning, developing, and proficient readers. Basic information and the level of competency status of the learners from the school year 2020-2021 were collected and used for the data entry of the developed ITS program.

\subsubsection{Tutoring model}

The tutoring model exemplifies teaching strategies or the pedagogical approach of the ITS system and includes methods for encoding reasoning about the feedback. Researchers consult the assigned teachers for reading comprehension intervention and assessment programs to give different pedagogical approaches or teaching strategies and feedback to be used and integrate into the system as an intervention learning and assessment process. 


\title{
3.3.4 User Interface model
}

The information stored in the database of a knowledge domain and student model is presented in the user interface of the developed ITS program. The relevant output of the models during the learning and assessment process is presented to the learners with this interface. The developers and researcher of the ITS developed and designed a userfriendly, easy to understand and pleasant user interface of the ITS based on the collected ideas and concepts from the teachers and instructional developer experts. The developers and researchers used a dropdown menu and buttons to easily navigate the system and enhanced with the dynamic graphics and colors for the design of the ITS interface.

In the implementation phase, during the implementation process, grade 7 learners and assign teachers in the reading comprehension intervention and assessment program were asked to try and test the developed ITS program.

In the Evaluation phase, the Acceptability, Validity, and Technical Acceptability of the ITS were measured using the survey questionnaire in this stage. The learner and teacher respondents were asked to evaluate and validate the ITS based on the given criteria wherein based and taken from the collaborative ideas of teachers and experts.

The acceptability, validity, and technical acceptability signify the efficiency and accuracy of the developed ITS to provide effective solution and intervention for those struggling learners in reading comprehension, and eventually, to deliver particular importance on a feasibility study that implemented not only in Catablan Integrated School but in entire Schools division of Urdaneta.

Feedback was used from the respondents as a basis for the improvement of the validity and acceptability of the developed ITS program.

\subsection{Participants of the Study}

In this study, three (3) Junior High School English major teachers, 30 Grade 7 learners enrolled in the school year 2020-2021, are the respondents. The fifteen (15) learners were identified as beginner readers, and the (15) fifteen remaining learners are proficient readers. At the same time, the three (3) junior high school teachers assigned to reading comprehension intervention and assessment programs were chosen on purpose. For data collection and analysis, learners and teachers filled out survey questionnaires on Google forms, enabling researchers to evaluate teacher's and learner's validity, acceptability, technical acceptability, usability in using developed ITS, and perceived objectives and needs in the system's development.

\subsection{Statistical Analysis}

The data was collected with the use of a Likert-type evaluation tool. The Likert scale is a type of rating scale used to evaluate people's opinions, attitudes, and behaviors. The collected data in validity, acceptability of developed ITS using this tool were examined and validated by a validator to create a valid product used in development tests.

\subsubsection{An average weighted mean}

An average weighted mean is a mean that is calculated by applying different weights to different individual values. If all the weights are equal, the weighted mean is the same as the arithmetic mean.

Formula:

The formula for Average weighted Mean is:

$A W M=T W P / N$

Where:

$A W M=$ Average Weighted Mean

$W P \quad=$ Number of respondents per column multiplied by the assigned numerical value

$T W P=$ The sum of the products in the column

$N \quad=$ The number of respondents

The following scale was used, and the average weighted mean were further analyzed and interpreted.

\subsubsection{Content Validity and Acceptability, Technical Quality Acceptability and usability}

$\begin{array}{cc}\text { Values } & \text { Mean Scale } \\ 4 & 3.26-4.00 \\ 3 & 2.51-3.25 \\ 2 & 1.76-2.5 \\ 1 & 1.00-1.75\end{array}$

\author{
Descriptive Equivalent (DE) \\ Strongly Agree (SA) \\ Agree (A) \\ Disagree (D) \\ Strongly Disagree (SD)
}

\author{
Descriptive Interpretation \\ Valid \\ Valid \\ Not Valid \\ Not Valid
}

Response ranging from 1.00 to 2.5 will be interpreted as not valid or not acceptable. 


\section{Results and Discussion}

This chapter has overseen the researchers' data presentation. This study aims to develop and validate the reading comprehension Intelligent Tutoring System for Grade 7 Students. This system was designed and developed using the ADDIE instructional design model and Classical ITSs architecture development process. Data were analyzed, and records were reviewed to address the questions presented in the statement of the problem.

\subsection{Learners struggle in reading comprehension.}

One of the problems encountered by CIS is the high number of learners who were categorized as for beginners base on the result of reading comprehension assessment in the past school year 2018-2019 and 2019 -2020. In this note, the researcher's objective is to find some solution to solve this problem encountered. The researchers collected the summary results of the reading assessment to find who among the learners of Catablan Integrated School are struggling in reading comprehension.

Table 1. Summary Result of Reading Assessment S.Y. 2018-2019

\begin{tabular}{|c|c|c|c|c|}
\hline Level & No. Of Cases & Beginning & Developing & Proficient \\
\hline Grade 7 & 91 & 32 & 29 & 30 \\
\hline Grade 8 & 77 & 15 & 22 & 40 \\
\hline Grade 9 & 91 & 23 & 31 & 37 \\
\hline Grade 10 & 67 & 17 & 19 & 31 \\
\hline Grade 11 & 59 & 20 & 12 & 27 \\
\hline Grade 12 & 43 & 16 & 10 & 17 \\
\hline
\end{tabular}

Table 2. Summary Result of Reading Assessment S.Y. 2019-2020

\begin{tabular}{|c|c|c|c|c|}
\hline Level & No. Of Cases & Beginning & Developing & Proficient \\
\hline Grade 7 & 72 & 25 & 20 & 27 \\
\hline Grade 8 & 89 & 15 & 30 & 44 \\
\hline Grade 9 & 74 & 14 & 20 & 40 \\
\hline Grade 10 & 89 & 12 & 30 & 47 \\
\hline Grade 11 & 49 & 21 & 10 & 18 \\
\hline Grade 12 & 55 & 13 & 14 & 28 \\
\hline
\end{tabular}

Tables 1 and 2 show the summary result of reading assessment in the school year 2018-2019 and 2019-2020. The learners will read the short story, then answer the comprehension questions prepared by the core group in the reading assessment. The evaluator will score the learners base on the answered questions. The learners will categorize as beginners if they got 58\% and below scores, developing if they got 59-79\% scores then $80-100 \%$ for proficient. Table 1 and 2 show that grade 7 learners got a high number of struggling learners in reading comprehension.

\subsection{ITS perceived features}

Table 3. Intelligent Tutoring System perceived features by the English teacher and students

\begin{tabular}{|c|c|c|c|c|}
\hline \multirow{2}{*}{ ITS Content } & \multicolumn{2}{|c|}{ Teachers } & \multicolumn{2}{|c|}{ Students } \\
\hline & Freq Count & $\%$ & Freq Count & $\%$ \\
\hline (1) User interface design - easy to access, understand, and use. & 3 & $100 \%$ & 29 & $97 \%$ \\
\hline $\begin{array}{l}\text { (2) Use log-in to secured the user of the system-teacher as the admin } \\
\text { account, and student's account. }\end{array}$ & 3 & $100 \%$ & 25 & $83 \%$ \\
\hline (3) Text - To present the concepts and theories. & 3 & $100 \%$ & 27 & $90 \%$ \\
\hline (4) Video - Synchronize video with content to reinforce concepts. & 3 & $100 \%$ & 27 & $90 \%$ \\
\hline (5) Audio - use audio to read the passage/lesson presented. & 3 & $100 \%$ & 26 & $87 \%$ \\
\hline $\begin{array}{l}\text { (6) Graphics displaying art and image data effectively and meaningfully } \\
\text { to the user. }\end{array}$ & 2 & $67 \%$ & 23 & $77 \%$ \\
\hline $\begin{array}{l}\text { (7) Quizzes - Make every quiz interesting using different types of } \\
\text { questions. }\end{array}$ & 3 & $100 \%$ & 28 & $93 \%$ \\
\hline \multicolumn{5}{|l|}{ (8) Feedback } \\
\hline (8.1.) Provide feedback to verify the correctness & 3 & $100 \%$ & 30 & $100 \%$ \\
\hline (8.2.) Provide feedback immediately following a response & 3 & $100 \%$ & 30 & $100 \%$ \\
\hline (8.3.) Provide encouraging feedback & 3 & $100 \%$ & 30 & $100 \%$ \\
\hline
\end{tabular}


Table 3 shows the features that the teachers and learners want to have in Intelligent Tutoring System. Teachers want that the system should be easy to use or user-friendly; the user should have user log-in. Lesson content with video, audio, and text got the highest frequency count.

Different types of questions in quizzes got the highest number of counts as well. Feedback is needed as it got the highest number of counts. Moreover, Table 2 shows that student's wants in delivering the ITS lesson are the same as the teachers perceived.

\subsection{The Development of ITS}

The researcher developed of Reading Comprehension Intelligent Tutoring System for Grade 7 Students in Catablan Integrated School using the basic framework based on the classical framework of ITSs as a guide. We applied the three development models as the Content domain model, Student Model, and Tutoring model. In the content domain model, the researcher gathered learning resources, materials, and assessment tests to be used in the ITS content. In the student model, the researcher gathered data about the learners' basic information and knowledge skills status. For the teaching model, the researchers adopted different learning and teaching concepts and strategies for the intelligent tutor features of the ITS program.

Grade 7 students were identified as struggling in reading comprehension based on the result of the reading assessment in the school year 2018-2019 and 2019-2020 - many grade seven students were classified as beginners than developing and proficient compared to other grade levels. In line with this, they need lesson material that was suitable to their needs. The materials used in the ITS were provided by the English coordinator of Catablan IS. The lesson materials were classified based on the topics for beginner, developing, and proficient. The assessment was based on the lesson per level.

\subsection{ITS Learners Categorization}

In ITS, the students will take the pre-test first to determine the prior knowledge. The system will automatically determine the category of the students based on the student's score if beginner, developing, or proficient level. The learners will categorize as a beginner if they got 58\% and below scores, developing if they got 59-79\% scores, then 80 $100 \%$ for proficient. If the students are classified as beginners, they undergo intervention lessons. If the students master the lesson and pass all the assessments, they will go to a higher level, which is the developing level followed by proficient level. The same process will occur at the developing and proficient level. After all the levels, a post-test will follow to determine if the students learned and enhanced their reading comprehension using the system.

The following are the screenshots plates of the developed ITS:

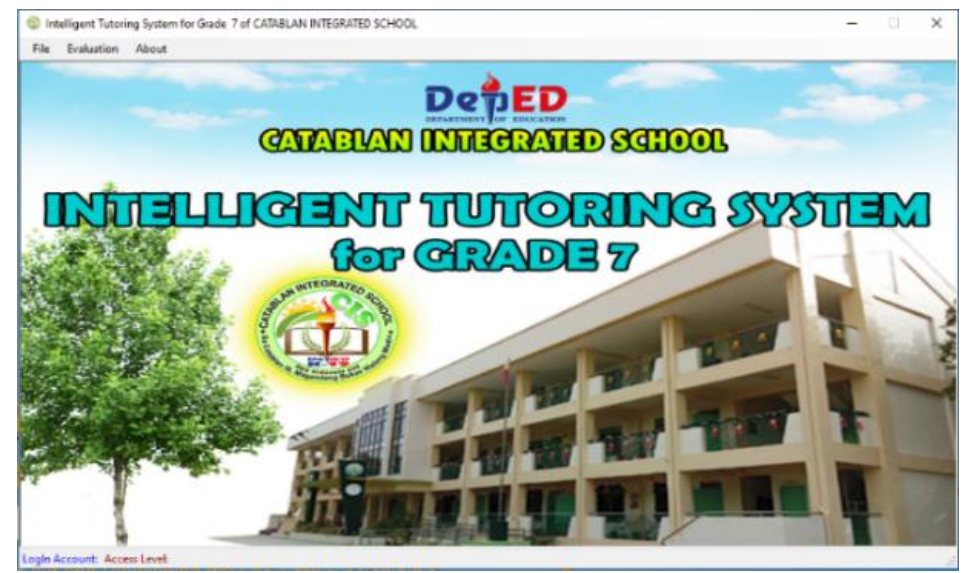

Fig.4. ITS Navigation system interface

Fig. 4 shows the Intelligent Tutoring System graphical user interface. The layout shows a simple background of the school. The upper left side shows the menu (file, evaluation, and about). The file button is used for logging in to the system. 


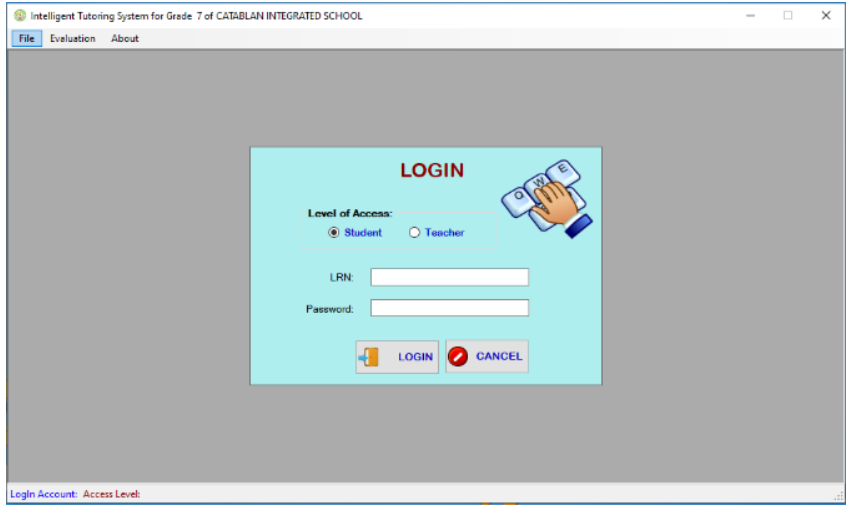

Fig.5. Teacher and learner log-in interface

Fig. 5 shows the screenshot of the log-in interface, which consists of two accounts for learners and teachers. The student should input their LRN and password to enter the system.

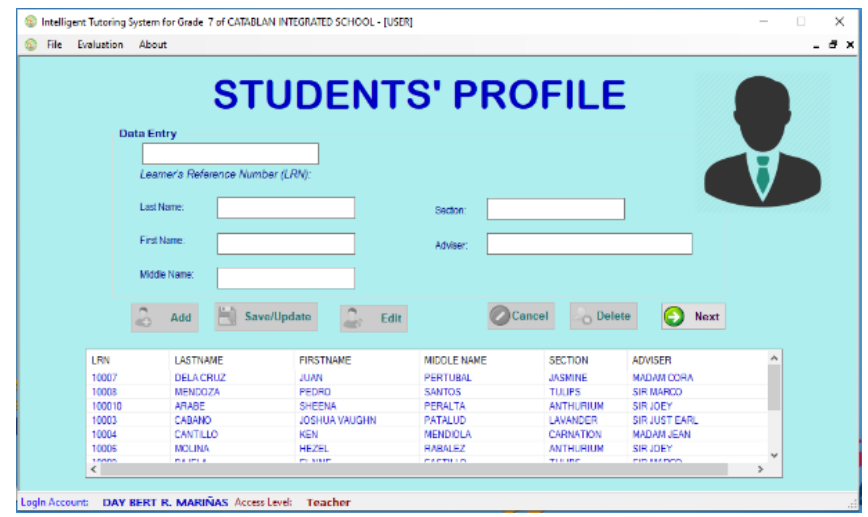

Fig.6. Adding student profile

Fig. 6 shows the interface for adding basic information and the user account of the learner.

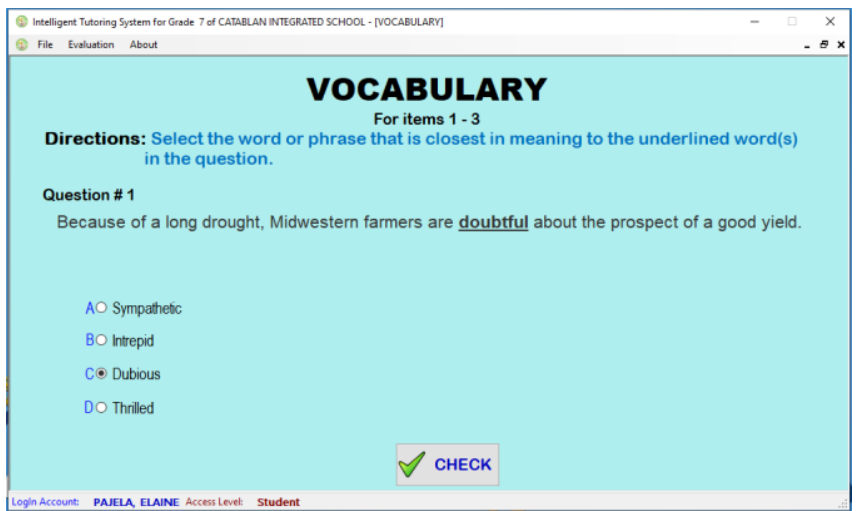

Fig.7. Pre-test assessment Interface

Fig. 7 shows the pre-test assessment interface to determine the level of competency of the learner. This part shows the test in vocabulary, and the learners should tick one answer to check if he/she is correct and proceed to the next question. 


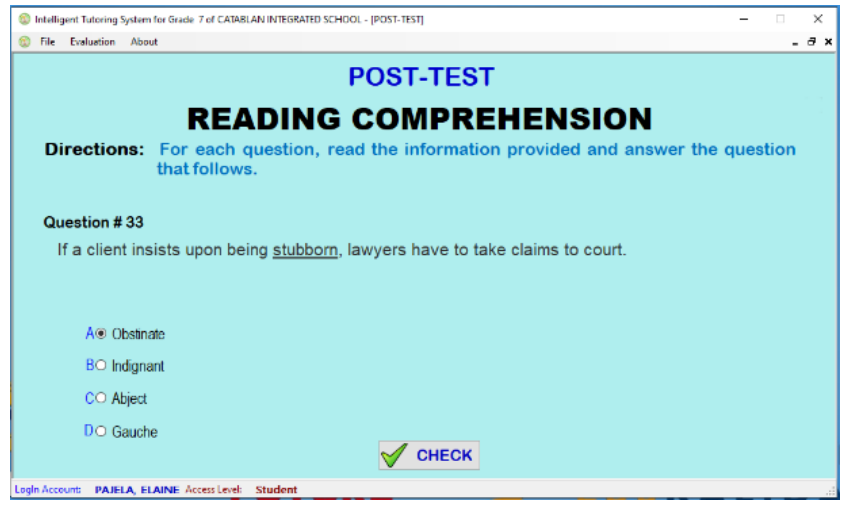

Fig.8. Result and feedback

Fig. 8 shows the result and feedback of the pre-test assessment, which identifies that the learner who answered the set of questions is a beginner.

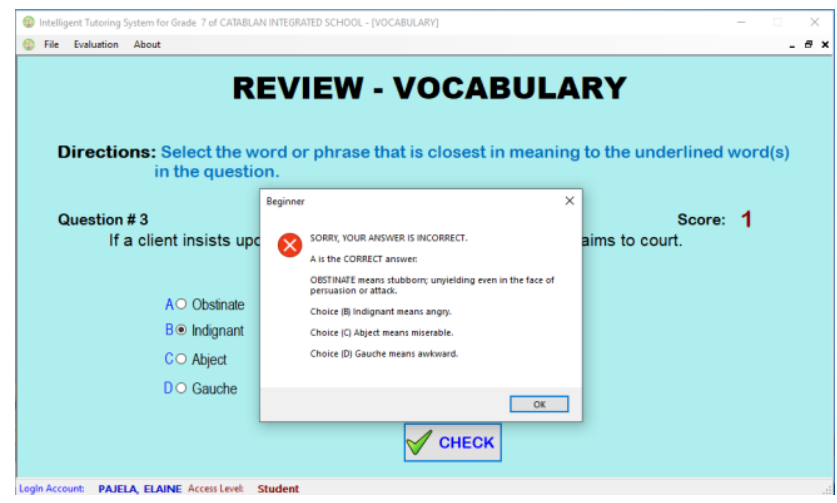

Fig.9. Beginning category

Fig. 9 shows the beginning category intelligent tutoring mechanism wherein the system identifies the wrong response from the learner's review for vocabulary. The system explained to the learner why he/she did not get the right answer and provided the right response to the question.

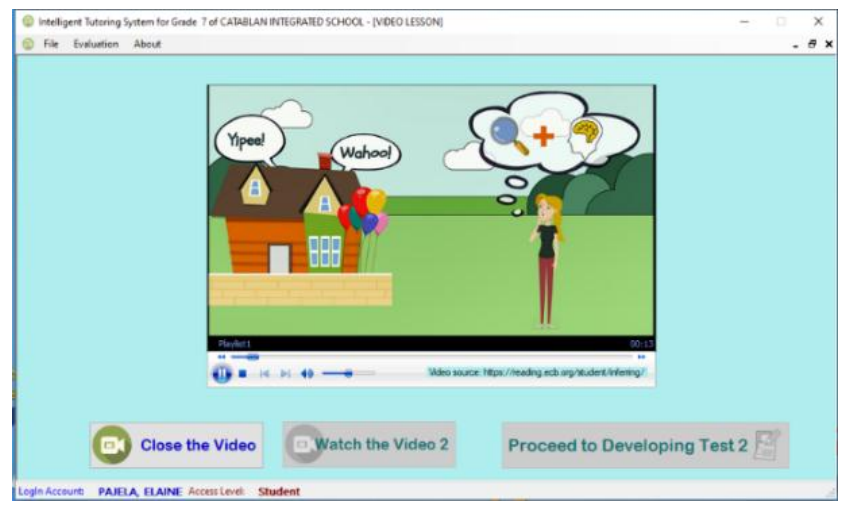

Fig.10. Audio and video learning content

Fig. 10 shows the audio and video learning content embedded in the system. A video presentation that contains a stop, pause, play button. The interface also has a "close the video" button if ever the student has finished watching the video, a "watch the video 2" button for the next video presentation, and a "Proceed to developing Test 2 " button. 


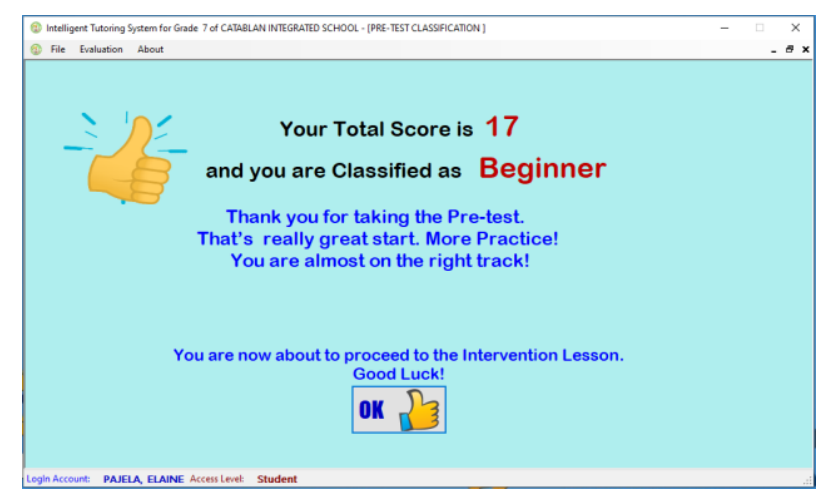

Fig.11. Post-test assessment Interface

Fig. 11 shows the post-test assessment interface, which has a radio button for the choices. The learners tick one answer here in the example screenshot. And to check the answer, the learner has a "check" button to proceed to the next task.

4.5 Acceptability of the Reading Comprehension Intelligent Tutoring System for Grade 7 Students in Catablan Integrated School for the teachers.

Content Validity and acceptability questionnaires for teachers were delivered as evaluated along with the following criteria: Correctness of content, efficiency, Interactivity, and overall design.

Table 4. Developed ITS Content Validity and Acceptability (Teacher)

\begin{tabular}{|l|c|c|c|}
\hline \multicolumn{1}{|c|}{ Criteria } & Average Weighted Mean & Descriptive Equivalent & Descriptive Interpretation \\
\hline 1.Correctness of content & 3.66 & Strongly Agree & Valid \\
\hline 2.Efficiency & 3.91 & Strongly Agree & Valid \\
\hline
\end{tabular}

Table 5. Developed ITS Technical Acceptability.

\begin{tabular}{|l|c|c|c|}
\hline \multicolumn{1}{|c|}{ Criteria } & Average Weighted Mean & Descriptive Equivalent & Descriptive Interpretation \\
\hline 1. Interactivity & 3.91 & Strongly Agree & Valid \\
\hline 2. Overall design & 4 & Strongly Agree & Valid \\
\hline
\end{tabular}

Table 4 indicates how respondents evaluated the content validity and acceptability of the developed ITS, with a rate of 3.78 indicating that the content validity and acceptability are valid. Teachers were also given technical quality questionnaires that were graded on the following usability criteria.

Table 5 shows how the respondents evaluated the usability of the developed ITS, with a rate of 3.89 which means it is valid.

Table 6. Developed ITS Usability

\begin{tabular}{|c|c|c|c|}
\hline Criteria & Average Weighted Mean & Descriptive Equivalent & Descriptive Interpretation \\
\hline (1) Usability & 3.86 & Strongly Agree & Valid \\
\hline
\end{tabular}

4.5.1 Acceptability of the Reading Comprehension Intelligent Tutoring System for Grade 7 Students in Catablan Integrated School for the learners.

Acceptability questionnaires were delivered and assessed along with the following criteria: efficiency, interactivity, overdesign, usability.

Table 7. Acceptability of ITS (Learners)

\begin{tabular}{|l|c|c|c|}
\hline \multicolumn{1}{|c|}{ Criteria } & Mean & Descriptive Equivalent & Descriptive Interpretation \\
\hline (1) Efficiency & 3.81 & Strongly Agree & Acceptable \\
\hline (2) Interactivity & 3.78 & Strongly Agree & Acceptable \\
\hline (3) Overall design & 3.89 & Strongly Agree & Acceptable \\
\hline (4) Usability & 3.89 & Strongly Agree & Acceptable \\
\hline
\end{tabular}


Table 7 shows the rate of the acceptability of the ITS, with a rate of 3.84 which means it is acceptable.

\section{Conclusion and Recommendation}

Through Intelligent Tutoring System (ITS), artificial intelligence is being implemented in the field of education. Nowadays, Intelligent Tutoring Systems are very significant in education because they are designed to monitor student progress, give next-step hints and select practice problems that help students learn new skills that are very useful to improve their overall school performance. The said ITS has a pre and post-test, wherein a pre-test determines the student's current level (Beginner, Developing, and Proficient) and a post-test if the student improved its reading comprehension based on the given series of activities the ITS. There were 33 participants, including the three JHS Teachers, particularly major English teachers Based on the result of reading assessment in the school year 2018-2019, Grade 7 students were identified as struggling in reading comprehension while in 2019-2020, many grade seven learners were classified as beginners than developing and proficient compared to other grade levels. Furthermore, teachers and students want the system to be user-friendly, have a user log-in, lesson content with text, audio and video as well as various types of questions in quizzes. The respondents also perceived that developed ITS is useful and the content is valid thus is very acceptable to be utilized by the learners. In addition, result reveals that student's reading comprehension could be improved and developed by the proposed ITS.

\section{Recommendation}

The researchers recommend that the ITS system should be tested and evaluated by the large group of learners together with the Education Program Supervisors and ICT department of the DepEd division office of Urdaneta City for the possible division implementation of the system. The researchers also recommend continuous program development by conducting related studies because it has been seen to be appropriate for system development. The researchers highly recommend that the ITS should be implemented in both public and private schools for their quarterly reading assessment and experience the innovative way of delivering learning using new trends technology. Further research is needed to improve the developed ITS or incorporate innovative features updates and emerging trends content into the Intelligent tutoring system for the benefit of the school.

\section{References}

[1] Elleman AM, Oslund EL. Reading comprehension research: Implications for practice and policy. Policy Insights from the Behavioral and Brain Sciences. 2019 Mar;6(1):3-11.

[2] Williamson SN. Development of a self-rating scale of self-directed learning. Nurse researcher. 2007 Jan 1;14(2).

[3] Chakraborty M, Nafukho FM. Strategies for virtual learning environments: Focusing on teaching presence and teaching immediacy. Internet Learning. 2015;4(1):2.

[4] Panconesi G, Guida M, editors. Handbook of Research on Teaching With Virtual Environments and AI. IGI Global; 2021 Feb 19.

[5] Spice B. New AI Enables Teachers To Rapidly Develop Intelligent Tutoring Systems [Internet]. 2020. Available from: https://www.cs.cmu.edu/news/new-ai-enables-teachers-rapidly-develop-intelligent-tutoring-systems

[6] Xu Z, Wijekumar K, Ramirez G, Hu X, Irey R. The effectiveness of intelligent tutoring systems on K - 12 students' reading comprehension: A meta - analysis. British Journal of Educational Technology. 2019 Nov;50(6):3119-37.

[7] Sedlmeier P. Intelligent Tutoring Systems. International Encyclopedia of the Social \& Behavioral Sciences. 2001;

[8] A. S. PISA 2018 Insights and Interpretations. 2018.

[9] Manlapig M. What's to blame for the low reading comprehension of the Filipino youth? [Internet]. 2020. Available from: https://www.cnn.ph/life/culture/2020/4/21/reading-comprehension-problem.html

[10] Miñoza MV, Montero MA. Reading Comprehension Level among Intermediate Learners. Online Submission. 2019;31(3):5618.

[11] Robot R. How Intelligent Tutoring Systems are Changing Education [Internet]. 2020. Available from: https://medium.com/@ roybirobot/how-intelligent-tutoring-systems-are-changing-education-d60327e54dfb

[12] Yüce A, Abubakar AM, İlkan M. Intelligent tutoring systems and learning performance: applying task-technology fit and IS success model.

[13] Veeravagu JV, Muthusamy C, Marimuthu R, Michael AS. Using Bloom's taxonomy to gauge students' reading comprehension performance. Canadian Social Science. 2010 Jun 25;6(3):205-12.

[14] Ben-Aharon A. What Is the Importance of Reading Comprehension After School? [Internet]. 2021. Available from: https://greatspeech.com/what-is-the-importance-of-reading-comprehension-after-school/

[15] Elleman AM, Oslund EL. Reading Comprehension Research: Implications for Practice and Policy. Policy Insights from the Behavioral and Brain Sciences. 2019;6(1):3-11. doi:10.1177/2372732218816339

[16] Xu Z, Wijekumar K, Ramirez G, Hu X, Irey R. The effectiveness of intelligent tutoring systems on K - 12 students' reading comprehension: A meta - analysis. British Journal of Educational Technology. 2019 Nov;50(6):3119-37.

[17] Handan AT. Intelligent Tutoring Systems (ITS) to Improve Reading Comprehension: A Systematic Review. Journal of Teacher Education and Lifelong Learning.;2(2):77-89.

[18] Wijekumar KK, Meyer BJ, Lei P. Web-based text structure strategy instruction improves seventh graders' content area reading comprehension. Journal of Educational Psychology. 2017 Aug;109(6):741. 
[19] Alhabbash MI, Mahdi AO, Naser SS. An Intelligent Tutoring System for Teaching Grammar English Tenses.

[20] Eryılmaz M, Adabashi A. Development of an Intelligent Tutoring System Using Bayesian Networks and Fuzzy Logic for a Higher Student Academic Performance. Applied Sciences. 2020 Jan;10(19):6638.

[21] Kearsley GP, editor. Artificial intelligence and instruction: Applications and methods. Addison-Wesley Longman Publishing Co., Inc.; 1987 Jan 1.

[22] Sierra E, García-Martínez R, Cataldi Z, Britos P, Hossian A. Towards a methodology for the design of intelligent tutoring systems. Research in Computing Science Journal. 2006;20:181-9.

[23] Diezmann C, Watters J. A theoretical framework for multimedia resources: A case from science education. InAARE 2002 Conference Papers 2002 (pp. 2-18). Australian Association for Research in Education.

[24] Aldoobie N. Technology integration and learning theory. American International Journal of Contemporary Research. 2015;5(6):114-8.

[25] Siemer J, Angelides MC. A comprehensive method for the evaluation of complete intelligent tutoring systems. Decision support systems. 1998 Jan 1;22(1):85-102.

[26] He, Huihua, Jin Liu, and Hongmin Ren. "Using Computer Aided Assessment System to Assess College Students Writing Skill." International Journal of Modern Education and Computer Science 3.2 (2011): 8.

[27] Kajitori, Kazuaki, Kunimasa Aoki, and Sohei Ito. "Developing a Compact and Practical Online Quiz System." International Journal of Modern Education \& Computer Science 6.9 (2014).

[28] Guo, Jing, and Jianping Zheng. "Computer Aided Instruction for Literature Courses Teaching." International Journal of Education and Management Engineering 1.6 (2011): 51.

\section{Authors' Profiles}

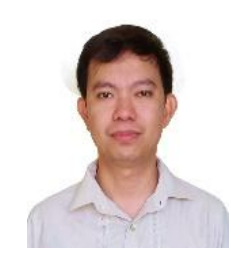

Day Bert R. Mariñas works as a Senior High School Teacher at Catablan Integrated School in Urdaneta City, Pangasinan, Philippines. He graduated from Pangasinan State University Urdaneta City Campus with a Bachelor of Science in Information and Communications Technology in 2012.

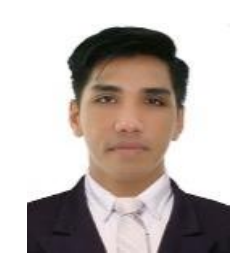

Roberto R. Coloma is currently working as a Senior High School Teacher in Lananpin National High School, Urdaneta City, Pangasinan, Philippines. He received the Bachelor of Arts in Information Technology at the Asian Institute of E-Commerce in Calasiao, Pangasinan. He also received a $2 \mathrm{yr}$ diploma in Computer Service Technician at Lyceum Northern Luzon. He passed the National certification level II in Computer Systems Servicing under the Technical Education and Development Authority (TESDA).

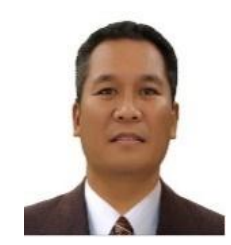

Lin V. Tadeja is currently a Senior High School teacher at Laoac National High School and in-charge of the Technical-Vocational and Livelihood Track. He received the Bachelor of Science in Computer Science at Marian Computer College at San Carlos City, Pangasinan. He was a former college instructor at Pangasinan State University, San Carlos City Campus, San Carlos City, Pangasinan.

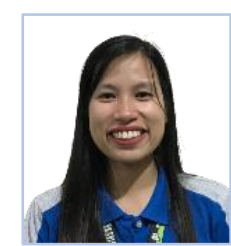

Shaira Marie J. Castillo received Bachelor in Business Teacher Education Major in Information Technology degree from Polytechnic University of the Philippines year 2017. She is currently working as a Teacher in Cipriano P. Primicias National High School at Alcala, Pangasinan, for almost three years.

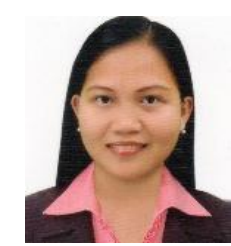

Katherine Dotimas Tan is currently working at the Department of Education as a Junior and Senior High School teacher in Eastern Pangasinan Agricultural College, Sta. Maria, Pangasinan, handling and teaching computer subjects. She graduated from Pangasinan State University, Asingan Campus, Asingan Pangasinan with a Bachelor's degree in Information and Communications Technology (BS ICT). She also finished and passed her Computer Systems Servicing NC II course at Wellcare Institute of Science and Technology, Urdaneta City, Pangasinan. At the same time, she finished her Trainer's Methodology (TM Level 1) at Maxima Technical and 
Skills Training Institute, Inc., Dagupan City, Pangasinan. She also took up her education units at Pangasinan State University, Urdaneta Campus, Pangasinan, and luckily passed her Licensure Examination for Teachers (LET) last September 2018. At present, she is taking up her Master of Arts in Education major in Computer Education at Pangasinan State University, Urdaneta Campus, Urdaneta City, Pangasinan.

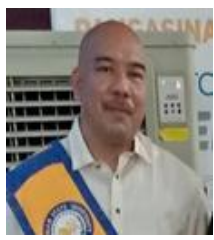

Frederick F. Patacsil received his B.Sc. degree from University of the Cordilleras (formerly Baguio Colleges Foundation) in 1993. He received his M.Sc. degree and Doctor in Information Technology from University of the Cordilleras. He is currently the Dean of College of Computing in Pangasinan State University - Urdaneta City Campus.

How to cite this paper: Day Bert R. Mariñas, Roberto R. Coloma, Lin V. Tadeja, Shaira Marie J. Castillo, Katherine D. Tan, Frederick F. Patacsil, "Development of an Intelligent Tutoring System for English Reading Comprehension: Design Based on Philippine Public School Flexible Learning Experience", International Journal of Information Engineering and Electronic Business(IJIEEB), Vol.13, No.5, pp. 9-23, 2021. DOI: 10.5815/ijieeb.2021.05.02 